\title{
Effects of living yeasts on zootechnical performance and carcass composition of finishing bulls
}

\author{
J Aerts ${ }^{1}$, J Latré 1, L Dussert ${ }^{2}$ \\ 1 Technical State University CTL, Voskenslaan 270, 9000 Gent, Belgium; \\ 2 Co Lesaffre, 147, rue Gabriel-Péri, BP 6027, 59706 Marcq-en-Baroeul cedex, France
}

To investigate the effect of a daily supplementation of $12 \mathrm{~g}$ living yeast (Saccharomyces Cerevisiae, strain 47; trade name Biosaf Sc 47), 30 finishing bulls were divided into comparable groups based on weight and growth rate (15 doublemuscled Belgian White and Blue bulls: 8 in control and 7 in yeast group; 15 Charolais cross bulls; 7 in control and 8 in yeast group). Feed intake, growth rate, feed conversion rate and slaughter characteristics were measured (table I). The animals were kept in loose housing on straw bedding $(2 \times 2$ pens) and received allmash + straw ad libitum. The experiment started at $534 \pm 67 \mathrm{~kg}$ live weight and lasted $102 \pm 17 \mathrm{~d}$. Live weight was individually measured 5 times during the trial and intake was measured daily for each pen. Percentage dressing was calculated as $\%$ of the cold carcass weight on the starved live weight. The $\%$ of the meat and fat in the carcass was determined by total dissection of the carcass.

Supplementation of living yeast had no influence on in vitro digestibility and net energy value of the allmash, and dry matter intake and feed conversion ratio were not altered. Daily live weight gain and dressing \% were not significantly influenced. However, supplementation of living yeast significantly increased meat percentage in the carcass, and the fat percentage was significantly decreased. A fitting explanation for this higher $\%$ of meat in the carcass was not found, but Gedek et al (1993) reported a strong increase in the Gram-negative microbial population in the rumen after supplementation with living yeast, and Wallace (1983) reported a higher digestibility for the Gram-negative compared with the Gram-positive bacteria. This may result in an enhanced flow of non-ammonia-nitrogen in the duodenum and an increased amino-acid resorption in the small intestine. This higher amino-acid resorption may have contributed to the observed higher percentage of meat.

Further experiments have to confirm if percentage of meat in the carcass can be enhanced by living yeast supplementation and whether this is a result of a higher number of Gram-negative rumen bacteria with a higher digestibility.

Table I. Zootechnical performance and carcass characteristics.

\begin{tabular}{lcc}
\hline Group & Control & Yeast \\
\hline DMI $(\mathrm{kg})$ & 8.91 & 9.06 \\
DLG $(\mathrm{kg})$ & $1.40^{\mathrm{a}}$ & $1.46^{\mathrm{a}}$ \\
FCR & 6.36 & 6.21 \\
$\%$ dressing & $69.4^{\mathrm{a}}$ & $69.3^{\mathrm{a}}$ \\
$\%$ meat & $67.9^{\mathrm{a}}$ & $72.0^{\mathrm{b}}$ \\
$\%$ fat & $18.7^{\mathrm{a}}$ & $15.6^{\mathrm{b}}$ \\
\hline
\end{tabular}

a, b $P<0.05 ; D M I, D L G$ and FCR = dry matter intake, daily live weight gain and feed conversion ratio $(\mathrm{kg}$ $\mathrm{DM} / \mathrm{kg} \mathrm{DLG}$ ), respectively.

Gedek B, Enders C, Ahrens F, Roques C (1993) Ann Zootech 42, 2, 175

Wallace RJ (1983) Br J Nutr 49, 101-108 